Www.jmscr.igmpublication.org

Index Copernicus Value: 79.54

ISSN (e)-2347-176x ISSN (p) 2455-0450

crossref DOI: https://dx.doi.org/10.18535/jmscr/v7i4.05

Journal Of Medical Science And Clinical Research

IGM Publication

An official Publication of IGM Publication

\title{
To study the effectiveness of EMLA in the alleviation of pain during Hepatitis $B$ vaccination given at birth
}

\author{
Authors \\ Dr Hitender Gautam ${ }^{1}$, Dr Deepak Sharma ${ }^{2}$, Dr Rakesh Sharma ${ }^{3}$, Dr Pancham Kumar ${ }^{4}$, \\ Dr Priyanka ${ }^{5}$ \\ ${ }^{1}$ Resident, Department of Paediatrics, IGMC, Shimla, Himachal Pradesh, India \\ ${ }^{2}$ MBBS student, Maharishi Markendeshwar University Solan (H.P) \\ ${ }^{3}$ Professor Department of Paediatrics, IGMC, Shimla, Himachal Pradesh, India \\ ${ }^{4}$ Assistant Professor Department of Paediatrics, IGMC, Shimla, Himachal Pradesh, India \\ ${ }^{5}$ Resident, Department of Community Medicine, IGMC, Shimla, Himachal Pradesh, India \\ Corresponding Author \\ Dr Priyanka \\ Resident, Department of Community Medicine, IGMC, Shimla, Himachal Pradesh, India
}

\begin{abstract}
Background and Aims: Effective pain management is a desirable standard of care for newborns and may potentially improve their clinical and neurodevelopmental outcomes. Neonatal pain should be assessed routinely using context-specific, validated and objective pain methods, despite the limitations of currently available tools. Reducing invasive procedures, and using pharmacological, behavioural or environmental measures can be used to manage neonatal pain. Hepatitis-B vaccines are given to all newborns under the universal immunization program. So the present study was planned to know the effectiveness of EMLA in alleviating pain during Hepatitis B vaccination given at Birth.

Methods: 280 neonates were enrolled for the study who are meeting study criteria out of all the newborns who received Hepatitis $B$ vaccine given at birth during study period. They were divided into two groups each with 140 participants. Group 1 had received hepatitis B vaccine after application of EMLA Ihour prior to a vaccine (case group)and group 2 received vaccine after application of placebo (control group). The pain was assessed on NIPS scale in both the groups immediately after immunization, at 30 second and at 60 second after immunization.
\end{abstract}

Results: NIPS scores at all the intervals were significantly lower when the vaccine was given after EMLA (Group 1) compare to group 2 who was immunized after placebo ( $P$ value of $<0.0001)$

Conclusion: Pain perceived by the newborn after EMLA application during hepatitis $B$ vaccine was less as compared to the placebo group.

Keywords: neonatal infant pain scale score (NIPS), Hepatitis B vaccine, intramuscular, EMLA (eutectic mixture of lidocaine and prilocaine).

\section{Introduction}

Pain is defined as an unpleasant sensory and emotional experience associated with actual or potential tissue damage Pain in children is mostly underestimated all around the world and often suboptimal managed $^{1,2}$. Children experiences pain 
as a result of injury, illness, during medical procedures and vaccination.

Vaccination are considered as the safest and most effective way to prevent serious illness and death ${ }^{3}$. Vaccination prevent approximately 2.5 million death every year, globally ${ }^{4}$ Various vaccines are given under universal immunisation programme and most of them are administered through parenteral routes. These vaccines are the most common source of unavoidable repeated iatrogenic pain in children. ${ }^{4}$

Health care providers are not sensitized pain in neonates and consider it's a benign procedure which require no intervention, on the contrary these repeated injections maycause short-term and long-term effects. They also include physiological changes such as apnoea, bradycardia, tachycardia, skin colour changes, sweating palms, increased respiration rate and muscular tonicity, increased intracranial pressure and behavioural changes, crying, sleep disturbances, feeding problems 5 . This led to intense anxiety regarding vaccination that may result in non-adherence to the recommended vaccination schedule ${ }^{6,7}$

In last few decades different techniques are evolved to reduce pain during various interventions in neonates which includes nonpharmacological methods like distractions, (video, music, tactile, blowing) sucrose solution or breast milk, patient positioning, vaccination $\mathrm{pH}$ and pharmacological like lignocaine gel or spray, EMLA, opioids.

EMLA cream was in use from 1980 for relieving pain neonates and children. EMLA Cream (lidocaine $2.5 \%$ and prilocaine $2.5 \%$ ) is an emulsion in which the oil phase is a eutectic mixture of lidocaine and prilocaine in a ratio of $1: 1$ by weight. It is used to relieve pain during lumber puncture, intra venous, intra arterial cannulation intra muscular injection. ${ }^{8,9,10}$ It was also used for reduction of pain during vaccination in infants and children. There are very few studies in which effect of EMLA was studied on new born during vaccination. So, the present study was conducted to know the effect of EMLA in reducing pain in newborn during vaccination.

\section{Aims and Objectives}

To study the effectiveness of EMLA in alleviating pain during Hepatitis B vaccination given at birth.

\section{Material and methods}

The study was conducted in the department of paediatrics Kamla Nehru State Hospital for Mother and Child Shimla.

This was a prospective and interventional randamized comparative double blinded study conducted among healthy full term newborns. The study was conducted over a period of one year from $1^{\text {st }}$ September, 2017 through $31^{\text {st }}$ August ,2018.

The study shah et al observed standardized mean difference of modified behavioral pain scale ranges from -.37 to -.53 . Taking this value as reference, the minimum required sample size with $80 \%$ power of study and two-sided alpha of $5 \%$ was 136 patients per group. So, sample size taken is 280 (140 per group).

\section{Inclusion criteria}

Healthy term newborns babies born at Kamla Nehru Hospital during the study period who received hepatitis $B$ vaccine at birth after informed consent regarding the procedure and drugs used.

\section{Exclusion criteria}

1) Gestation less than 37 weeks, IUGR baby.

2) Newborn with any kind of illness.

3) Newborn requiring any kind of supportive treatment after birth.

4) Newborn with any major congenital malformations.

5) Newborn to those mothers who receive any drug which cause CNS depression in the baby.

6) Newborn whose parent/ guardians refuse to give the consent for the study.

The demographic profile of the all the cases was recorded as per a structured case recording format. 
The newborns were randomly divided into two groups.

Group 1: Included newborn whom EMLA patch was applied one hour prior to hepatitis B vaccination and act as cases for the study.

Group 2: Included newborn whom placebo patch was applied one hour prior to hepatitis vaccination and considered as controls for group 1 .

Placebo patch used was identical to EMLA patch in its consistency, colour and odour.

The parents, as well as observer was not aware of which treatment was received by the neonate making the study double blinded. The person involve in randomization was not involved further in the study.

Newborn was laid down on the radiant warmer during whole procedure and was breastfed half hour before vaccination. Vaccine was given to those newborns who were at the 3-4 brazilton stage of arousal ${ }^{11}$ on the same surrounding and at the same examination table. EMLA patch or placebo was applied before vaccination depending on the group assigned after randomization. All the injections will be administered by the same staff nurse gently. EMLA cream $1 \mathrm{gm}$ were uniformly applied to an area of 1 square inch at the vaccination area (lateral region of right thigh) and covered with an occlusive dressing (Tegaderm) for 60 to 90 minutes $^{12}$, the dressing was removed before procedure, the skin was wiped dry. $0.5 \mathrm{ml}$ of Hepatitis B vaccine was be administered intramuscularly at the anterolateral aspect of thigh using $0.60 \times 25 \mathrm{~mm}$ needle.

The primary outcome measures neonatal pain had been assessed using Neonatal Infant Pain Scale (NIPS), a reliable tool to assess neonatal pain ${ }^{13}$. NIPS score of zero was ensured before vaccination and used as baseline for further comparison. NIPS score was observed immediately after the vaccine, at 30 second, and at one minute after administration of vaccine.

Categorical variables were presented in number and percentage (\%) and continuous variables was presented as mean \pm SD and median. Normality of data was tested by Kolmogorov-Smirnov test. If the normality is rejected then non parametric test was used.

Statistical tests were applied as follows:

1) Quantitative variables was compared using Unpaired t-test/Mann-Whitney Test (when the data sets were not normally distributed.) between the two groups.

2) Qualitative variables was compared using Chi-Square test /Fisher's exact test.

A $p$ value of $<0.05$ was considered statistically significant.

The data was entered in MS EXCEL spreadsheet and analysis was done using epi info version 7.2.2

\section{Results}

We enrolled a total of 280 participants in our study divided in two groups. Each group had 140 newborns.

Table 1: comparison of gender distribution between group 1 and group 2

\begin{tabular}{|l|c|c|c|c|c|}
\hline & \multicolumn{2}{|c|}{ Group 1 } & \multicolumn{2}{c|}{ Group 2 } & \multirow{2}{*}{ P value } \\
\cline { 1 - 5 } Gender & Frequency & Percentage & Frequency & Percentage & \\
\cline { 1 - 5 } Males & 73 & $52.14 \%$ & $\mathbf{7 0}$ & $\mathbf{5 0 \%}$ & \multirow{2}{*}{0.71} \\
\hline Females & 67 & $48.91 \%$ & $\mathbf{7 0}$ & $\mathbf{5 0 \%}$ & \\
\cline { 1 - 4 }
\end{tabular}

In group 1 total 140 neonates were participated, out of which $52.14 \%$ were males and $49 \%$ were female as compared to group 2 in which out of 140 neonates $50 \%$ were male and $50 \%$ female.
The difference of gender between two group statistically not significant. Hence both the groups were comparable 
Table 2: Comparison of different variables presents at birth between group 1 and group 2 given below:

\begin{tabular}{|c|c|c|c|c|}
\hline S.no & Variable & $\begin{array}{c}\text { Group 1 } \\
\text { Mean } \pm \text { SD }\end{array}$ & $\begin{array}{c}\text { Group 2 } \\
\text { Mean } \pm \text { SD }\end{array}$ & P value \\
\hline $\mathbf{1}$ & Birth weight & $2.7871 \pm 0.2986$ & $2.8864 \pm 0.3353$ & $\mathbf{0 . 1 7}$ \\
\hline $\mathbf{2}$ & Age in hours & $13.9571 \pm 4.8367$ & $14.8214 \pm 5.7568$ & $\mathbf{0 . 1 7}$ \\
\hline $\mathbf{3}$ & Gestational age & $38.5429 \pm 0.9846$ & $38.8000 \pm 1.0402$ & $\mathbf{0 . 5 1}$ \\
\hline $\mathbf{4}$ & OFC & $33.7114 \pm 0.9991$ & $33.5643 \pm 0.7839$ & $\mathbf{0 . 1 7}$ \\
\hline $\mathbf{5}$ & Length & $48.9429 \pm 1.1044$ & $48.5893 \pm 1.0253$ & $\mathbf{0 . 3 8}$ \\
\hline
\end{tabular}

Both the groups were comparable on the basis of demographic and anthropometric profile as mentioned in table 2.

Table3: Comparison of means of NIPS score of group 1 with group 2

\begin{tabular}{|l|c|c|c|}
\hline Group & $\begin{array}{c}\text { NIPS score at 0 seconds } \\
\text { Mean } \pm \text { SD }\end{array}$ & $\begin{array}{c}\text { NIPS score at 30 seconds } \\
\text { Mean } \pm \text { SD }\end{array}$ & $\begin{array}{c}\text { NIPS score at 60 seconds } \\
\text { Mean } \pm \text { SD }\end{array}$ \\
\hline hepatitis with EMLA (1) & $4.7071 \pm 1.2203$ & $1.7429 \pm 1.1957$ & $1.7429 \pm 0.6483$ \\
\hline Hepatitis with Placebo (2) & $5.3857 \pm 1.3281$ & $3.3786 \pm 1.1154$ & $1.5571 \pm 0.8837$ \\
\hline P value & $<0.001$ & $<0.001$ & $<0.001$ \\
\hline
\end{tabular}

NIPS score was observed in group 1 and group 2 at $0 \sec 30$ seconds and 60 seconds after Hepatitis $B$ vaccination. It was found that mean NIPS score in group 1(Hepatitis B vaccination after EMLA) was $4.7071 \pm 1.2203, \quad 1.7429 \pm 1.1957$ and $1.7429 \pm 0.6483$ which was significantly less as compared to group 2(Hepatitis B vaccine after placebo) where we observed the mean NIPS score was $5.3857 \pm 1.3281, \quad 3.3786 \pm 1.1154$ and $1.5571 \pm 0.8837$ at 0 sec 30 seconds and 60 seconds respectively with $\mathrm{p}$ value $<0.001$.

\section{Discussion}

Mean \pm SD of NIPS score in group 1(after application of EMLA before giving Hepatitis B vaccination) at 0,30 and 60 seconds were $4.70 \pm 1.22,1.74 \pm 1.19,1.74 \pm 0.65$ respectively and the mean of NIPS score of group 2 at 0,30 and 60 seconds were $5.39 \pm 1.33,3.38 \pm 1.12$ and $1.56 \pm 0.88$ respectively, which was significantly lower at all interval with $p$ value of $<0.001$. It concluded that application of EMLA significantly decrease pain during Hepatitis B vaccine (intramuscular injections).

These findings were comparable with study done by Taddio et al who used first cry and duration of cry as pain assessment tool reported a significant decrease in pain in the form of increase in the latency to first cry (MD, $0.90 \mathrm{sec} ; 95 \% \mathrm{CL}, .46$ to $1.34 ; \mathrm{P}<0.001)$ and decrease in duration of first cry $(\mathrm{MD},-1.30 \mathrm{sec} ; 95 \% \mathrm{Cl},-2.55$ to -0.05 ; $\mathrm{P}=0.04)$ for infant who received lidocain prilocaine versus a placebo during DPT vaccination at $6,10,14$ weeks, however they did not include newborns in their study ${ }^{2}$.

Similarly, Uhari nurses also reported a lower mean VAS pain score (range, $0-10 \mathrm{~cm})(2.5 \mathrm{vs}$ 3.8 ; $\mathrm{P}<0.003$ ) and VAS crying score (range, 0 $10 \mathrm{~cm})(2.8 \mathrm{P}<0.003)$ for infant who received lidocaine-prilocaine then for those who received placebo during DPT vaccination in infant. They also did not include newborns in their study and used VAS score for assessment of pain ${ }^{14}$.

In a study of lidocaine - prilocaine and no intervention, Dlli et al, reported a significant reduction in the NIPS score (range, 3-7) (MD, $4.0095 \% \mathrm{cCl},-4.83$ to $-3.17 ; \mathrm{P}<0.001)$ in infants 6 to 12 months of age and in the CHEOPS score (range , 4-13) (P .001; data $=\mathrm{NR})$ during different vaccines Hep B at $0-2$ weeks, at 1 and 6 month, MMR at 9 months ${ }^{15}$.

\section{Conclusion}

Pain perceived during both Hep B and BCG vaccine was less when vaccination was done after EMLA application, which concluded that EMLA is effective modality in alleviating pain during vaccination through intramuscular as well as intradermal route. 


\section{Recommendation}

EMLA is an effective pain alleviating modality and can be considered as pain reliving modalities during routine immunisation. This will decrease immediate as well as late neurodevelopmental complication in children due to repeated unavoidable pain during vaccination. This will also decrease parents anxiety regarding pain during vaccination and increase adherence to vaccination.

\section{References}

1. Paediatrics \& Child Health Division, The Royal Australasian College of Physicians. Guideline statement: management of procedure-related pain in children and adolescents. J Paediatr Child Health 2006; 42(suppl. 1): S1-S29

2. Taddio A, Manley J, Potash L, et al. Routine immunization practices: use of topical anesthetics and oral analgesics. Pediatrics 2007; 120: e637-e643.

3. Institute of Medicine (homepage on the internet). Childhood immunization schedule and safety: stakeholder concerns , scientific evidence, and future studies. Updated January 16,2013 . available from :http://www.iom.edu/reports/2013/The childhood -immunization-schedulesafety.aspx. Access July 14, 2014.

4. World Health Organization. World health assembly endorses new plan to increase global access to vaccines [press release]. Geneva: World Health Organization; [May 25,2012].Availablefrom: http://www.who. int/immunization/newsroom/press/wha_en dorses_gvap/en. Accessed July 14, 2017.

5. Mitchell A, Boss BJ. Adverse effects of pain on the nervous systems of newborns and young children: a review of the literature. J Neurosci Nurs. 2002 Oct; 34(5) :228-36.
6. Brady K, Avner JR, Khine H. Perception and attitude of providers towards pain and anxiety associated with pediatric vaccine injection. Chn pediatr; 2011;50(2):140143.

7. Luthy KE, Beckstrand RL, Asay W, Hewett C. Vaccination parent experience vaccine anxiety too. J AM Assoc Nurse Pract. 2013;25(12):667-673.

8. Gourrier E, Karoubi P, EI Hanache A, et al. Use of EMLA cream in premature and full term newborn infants, JAMA. 1993;270:850-853.

9. Halperin DL, Koren G, Attias. D, Pelegrini E, Greenberg ML, Wyss M. Topical skin anaesthesia for venous, subcutaneous drug resorvior and lumber puncture in children, Paediatrics. 1998; 101:1-9.

10. Pereira AL, GuinsburgR, de Almeda MF, Monterio AC, dos Santos AM, Kopelman, BI. Validity of behavioural and physiological parameter for acute pain assessment of term newborn infants. Sao Paula Med J.1999;117;72-80.

11. Brazelton TB, Nugent JK. The Neurobehavioural Assessment Scale. 3 rd ed. London: Mac Keith Press; 1995.

12. EMLA EMLA FDA available on (https://www.accessdata.fda.gov/drugsatfd a_docs/label/2000/19941s11lbl.pdf) last accessed 18.03.2019

13. Lawrence J, Alcock D, McGrath P, KayJ, MacMurray SB, andDulberg C. The development of a tool to assess neonatal pain. Neonatal Netw. 1993 Sept; 12(6): 59-66.

14. Uhari M. A eutectic mixture of lidocaine and prilocaine for alleviating vaccination pain in infants. Pediatric 1993; 719- 721.

15. Dilli D, Göker Küçük I, Dallar Y. Interventions to reduce pain during vaccination in infancy. J Pediatr. 2009; 154:385-390. 